\title{
Characterisation of a novel paralog of scavenger receptor class B member I (SCARB1) in Atlantic salmon (Salmo salar)
}

\author{
Hilde Sundvold ${ }^{1 *}$, Hanna Helgeland ${ }^{1}$, Matthew Baranski ${ }^{2}$, Stig W Omholt ${ }^{1}$ and Dag Inge Våge ${ }^{1}$
}

\begin{abstract}
Background: Red flesh colour is a unique trait found in some salmonid genera. Carotenoid pigments are not synthesized de novo in the fish, but are provided by dietary uptake. A better understanding of the molecular mechanisms underlying the cellular uptake and deposition of carotenoids could potentially be used to improve the low muscle deposition rate that is typically found in farmed Atlantic salmon. In addition, from an evolutionary point of view, the establishment and maintenance of this trait is still poorly understood. It has been demonstrated in several species that scavenger receptor class $B$, member 1 (SCARB1) is involved in intestinal absorption of carotenoids, which makes this gene a possible source of genetic variation in salmonid flesh pigmentation.

Results: In this study, a novel paralog of SCARB1 (SCARB1-2) was detected through screening for genetic variation in Atlantic salmon SCARB1. Full length SCARB1-2 encodes a protein with 89\% identity to Atlantic salmon SCARB1, except for the C-terminal cytoplasmic tail that shows only $12 \%$ identity. The most prominent site of SCARB1 mRNA expression was in the mid gut, while a five-fold lower level was detected in Atlantic salmon skeletal muscle and liver. The SCARB1-2 mRNA was equally expressed in liver, muscle and mid gut, and at a lower level than SCARB1 mRNA. A total of seven different SCARB1-2 alleles comprising repetitive enhancer of zeste motifs (EZH2) were identified in the founding parents of a resource Atlantic salmon population. We mapped the SCARB1-2 paralog to a region on Atlantic salmon chromosome 1, containing a putative QTL for flesh colour. Addition of the SCARB1-2 marker increased the significance of this QTL, however the large confidence interval surrounding the QTL precludes confirmation of SCARB1-2 as a causative gene underlying variation in this trait.

Conclusion: We have characterised a novel paralog of SCARB1 (SCARB1-2), have mapped it to Atlantic salmon chromosome 1 and have described its expression in various tissues. Mapping with SCARB1-2 alleles added further evidence for a QTL affecting flesh colour on this chromosome, however further studies are needed to confirm a functional role for this gene in flesh colour pigmentation.
\end{abstract}

\section{Background}

The most prominent quality characteristic of Atlantic salmon is the red/pink flesh colour that is caused by accumulation of carotenoids in the muscle [1]. Since no de novo synthesis of carotenoids occur in vivo, dietary supplied astaxanthin serves as the main source of carotenoids in farmed Atlantic salmon. Astaxanthin supplementation represents a considerable cost for the aquaculture industry [1], and the absorption and muscle

\footnotetext{
* Correspondence: Hilde.Sundvold@oslo-universitetssykehus.no ${ }^{1}$ Centre for Integrative Genetics, Dept. of Animal and Aquacultural Sciences, Norwegian University of Life Sciences, 1432 Aas, Norway Full list of author information is available at the end of the article
}

deposition efficiency is generally low $[2,3]$. Low to medium heritability estimates $\left(\mathrm{h}^{2}\right.$ mean $\left.=0.3\right)$ for flesh colour have been calculated for various salmonids (reviewed in [4]). An improved understanding of the genetic component of this trait and the molecular mechanisms involved could pave the way for more targeted selection for improved flesh pigmentation. Besides the commercial interest in this trait, the evolutionary basis of carotenoid deposition in the muscle of salmonids is still not well understood [5].

The processes involved in the intestinal uptake and transport of carotenoids in the blood serum are closely linked with that of fatty acids, and seem to be common

\section{Biomed Central}


in most carotenoid pigment-containing vertebrates [6-8]. Upon digestion, carotenoids are incorporated into mixed micelles [9], and carotenoid esters are hydrolyzed by bile salt-stimulated lipase [10] prior to absorption in the intestine. A fraction of the provitamin A carotenoids like beta-carotene are converted to vitamin $\mathrm{A}$, while the rest are reassembled together with fatty acids into chylomicrons that enter the blood and are transported in the circulation. Besides providing vitamin A [11,12], astaxanthin serves as a very potent antioxidant, effectively quenching singlet oxygen, scavenging free radicals, and preventing lipid peroxidation [13,14]. Astaxanthin is transported by the High Density Lipoprotein (HDL) and the Very High Density Lipoprotein (VHDL) fractions of the plasma of chum salmon, Oncorhynchus keta [15], and high levels of astaxanthin are observed in the plasma of salmonids [16]. Carotenoid accumulation in various tissues is observed in a wide range of animals and fish at varying levels $[17,18]$.

One approach applied for identification of genes contributing to complex traits is through screening for variation in biologically relevant candidate genes and analysing whether any of these are linked to the trait of interest. It has been suggested that flesh pigmentation in fish is controlled by a small number of genes with large non-additive effects [19]. Despite a scarce knowledge of molecular mechanisms involved in carotenoid flesh deposition in fish, Rajasingh et al., [5] predicted by mathematical modelling that the rate of carotenoid uptake into the muscle tissue, together with the intestinal uptake, have the highest influence on actual muscle pigment concentrations. Animal studies have identified an important role of the scavenger receptor class B, type 1 (SCARB1), in the intestinal absorption of dietary lipids [20]. In Atlantic salmon, a particularly high SCARB1 mRNA expression in the mid gut has been reported [21]. SCARB1 belongs to the ATP-binding cassette (ABC) transporter super-family, and in addition to lipoprotein, cell culture ligand binding studies show that SCARB1 recognizes and binds a diverse set of ligands with low substrate specificity, thus mediating the transport of many lipophilic substances [22,23]. The first evidence that SCARB1 was important for carotenoid transport was demonstrated in Drosophila, where a gene encoding a SCARB1 homologous protein is essential for the cellular uptake of carotenoids in this species [24]. It was later shown that SCARB1 facilitated the absorption of dietary $\beta$-carotene in mice $[24,25]$, and likewise in the human intestinal derived cell line Caco-2 cells [26,27]. Recently, a study in Bombyx mori, identified a transmembrane protein Cameo2, homologous to the mammalian $S C A R B 1$, as a specific carotenoid transporter in the silk worm. This species represents a model system for selective carotenoid transport due to the presence of several genetic mutants with defects in parts of this pathway that result in altered cocoon pigmentation. In mutant larvae, Cameo2 expression was strongly repressed in the silk gland, resulting in colourless silk glands and white cocoons. The authors propose that selective delivery of lutein to specific tissues requires the combination of Cameo2 as a transmembrane receptor on the surface of the cell and an intracellular carotenoid binding protein (CBP) [28].

The role of SCARB1 in carotenoid transport in homologous systems prompted us to investigate if SCARB1 has a role in flesh pigmentation in Atlantic salmon. A resource population derived from an ancient land-locked population and a commercial production strain of Atlantic salmon in Norway, with considerable phenotypic variation for this trait, were used as a source to screen for genetic variation and to map SCARB1-2 to the Atlantic salmon genome.

\section{Results}

\section{Identification of genetic variation in SCARB1-2}

The founder parents of the QTL-mapping population (P0 SALBANK) were screened for genetic variation within the non-coding parts of Atlantic salmon SCARB1 [Genbank: DQ914655.1]. Intron-exon junctions were deduced from comparative alignment to the human SCARB1 reference sequence [Genbank: NM_005505.4]. PCR-amplification of Atlantic salmon [Genbank: DQ914655.1] intron three, four, five and ten were performed using oligonucleotides as described in table 1 and revealed the presence of several amplicons in intron four, while no nucleotide variations were detected in the remaining introns. The intron four length polymorphisms comprise an constant amplicon of about $1.5 \mathrm{~kb}$, present in all subjects, and one to two additional amplicons ranging from 619 to $763 \mathrm{bp}$. DNA-sequencing revealed that the constant $1.5 \mathrm{~kb}$ amplicon equals the previously reported Atlantic salmon SCARB1 [Genbank: DQ914655.1]. The lower size amplicons were highly similar in sequence to the Atlantic salmon SCARB1. Novel oligonucleotides generated from the lower size amplicon-sequences confirmed the same amplification patterns as initially observed.

\section{Identification of a novel paralog of SCARB1, SCARB1-2}

The lower size amplicons of intron four potentially derive from a gene with high similarity to the coding sequence of $S C A R B 1$. In order to reveal the origin of these sequences, novel oligonucleotides were designed and used in RT-PCR, in combination with SCARB1 specific oligonucleotides. Further overlapping RT-PCR amplicons were generated using a combination of oligonucleotides highly similar to SCARB1, identified through the NCBI TRACE-archive sequences using Atlantic 
Table 1 Oligonucleotides

\begin{tabular}{|c|c|c|c|}
\hline Oligonucleotide combination & Oligonucleotide forward $\left(5^{\prime}-3^{\prime}\right)$ & Oligonucleotide reverse $\left(5^{\prime}-3^{\prime}\right)$ & Size $(b p)$ \\
\hline 1: Intron 3 & AGCGTCTTCAGAAGCAGAAC & CCACATCAGCTCTCCTACAG & 350 \\
\hline 2: Intron 4 & CTACGACAGCAAGCTGGTGGACTT & GGTCAAGCCGTTCCATGAGTTCAC & $600-700$ \\
\hline 3: Intron 5 & CTCCCCAGTGTAACATGATCAACGG & CAGATTGTCTGCAGGGACAGAAGC & 600 \\
\hline 4: Intron 10 & GGGAAGATCTCAGAGGTTGT & TACACCATCACCATTGGCAA & 500 \\
\hline 5: Exon 4 and 5 & CTACGACAGCAAGCTGGTGGACTT & GATGTCATCTTCGCCGGTATGGATT & 138 \\
\hline 6: CDNA & CGTTGGACCAATCATTATCGACA & TCTGTAGTGTAGTAGTACAGCTCCCAGAG & 1308 \\
\hline 7: CDNA & ATGAATAAATCTAAATTAGCGATCGGA & TGTCATCTTCGCCGGTATGGATT & 672 \\
\hline 8: CDNA & TGATGGAGAACTTGCCGTTCC & CCCTGCAGCACTGGGCTAGACT & 1054 \\
\hline
\end{tabular}

Oligonucleotides used for PCR-amplification, QTL-mapping and real-time PCR of the two SCARB1 paralogs in Atlantic salmon.

salmon SCARB1-sequence as a query [GenBank: DQ914655], in combination with the SCARB1-2 spesific sequence. In the end a cDNA-amplicon of $1309 \mathrm{bp}$, comprising n.p. 358-1666 of SCARB1 [GenBank: DQ914655], was obtained using oligonucleotide combination 6 (Table 1). A second RT-PCR using oligonucleotide combination 7 resulted in a PCR-amplicon comprising start codon at n.p. 281 to n.p. 953. Finally, a third amplicon was obtained using oligonucleotide combination 8 (Table 1), comprising n.p. 711-1765. The three above overlapping amplicons generated a transcript with an open reading frame extending from n.p. 281 to 1736 of SCARB1 [GenBank:DQ914655]. This full-length cDNA-sequence was blasted to the TRACEarchive and its sequence identity was confirmed for the SCARB1-2 cDNA at n.p.1-114, 417-833, 1001-1120, 1244-1343, and 1463-1612. The predicted protein shows 89\% identity to Atlantic salmon SCARB1 [GenBank: DQ914655] when comparing the sequence from aa 1 to 462. The remainder of the protein, extending from aa 463 until stop codon at position 486, only shares $12 \%$ identity to SCARB1. SCARB1-2 is eight aa shorter compared to SCARB1 (Figure 1). The cDNA sequence and translated SCARB1-2 in Atlantic salmon is submitted to [GenBank: HQ403588].

\section{Linkage mapping of SCARB1-2}

Genotyping of the six founding parents in the SALBANK population and the F2 progeny resulted in four amplifying alleles in the Bleke parents P11, P14 and P15 and three amplifying alleles in the commercial line parents P31, P34 and P35, ranging in size from 619 bp to 763 bp (table 2). Sequence-analysis revealed that the SCARB1-2 alleles comprise the zeste consensus motif [T/C]GAG[T/C][G/T]. The repetitive zeste-elements and their corresponding amplified alleles in the Bleke and the commercial Atlantic salmon parents are shown in table 2. Size determination of the SCARB1-2 alleles using fluorescently labelled oligonucleotides and capillary electrophoresis yielded no amplification products in parents P31, P34 and P35. These 'failed' amplifications were declared as 'null/null' genotypes, and when combined with the genotype patterns observed in the F2 progeny, it was possible to infer F1 parent genotypes with null alleles, and therefore Mendelian segregation in the F2 families. This strategy, however, meant that it was impossible to distinguish null/null genotypes from failed amplifications in F2 progeny. Nevertheless, based on high quality size standard profiles, and previous amplification success with other markers, null/null genotypes were inferred when no peaks were observed. SCARB1-2 mapped to chromosome 1 of the Atlantic salmon map [29] (Figure 2). Large differences in recombination rate were observed in the male and female maps, with the female map consisting of two unlinked segments (Chr1-F1 and Chr1-F2), while the male map had a higher level of recombination between marker OtsG83 and CL9726 than the female map.

\section{QTL (quantitative trait loci) analysis of SCARB1-2 alleles}

In the sire-based, across-family analysis, the QTL peak exceeded the chromosome-wide significance threshold (Figure 3), and the two parents M1 and M4 were found to be segregating for the QTL (table 3). In the dambased across-family analysis, the overall F-value of 2.26 was not significant (Figure 3). However, parent F4 demonstrated strong evidence for QTL segregation, with an absolute t-value of 3.0, and significant QTL linkage was found when this parent was analysed individually (data not shown). In both sire and dam based analyses, the $95 \%$ confidence interval for the QTL position covered the entire linkage group, however the actual QTL peaks were $9 \mathrm{cM}$ from $S C A R B 1-2$ in the male analysis and $2 \mathrm{cM}$ from $S C A R B 1-2$ in the female analysis. After correction for an approximate selective genotyping fraction of 0.5 (averaged over families), the QTL explained $4.4 \%$ of the phenotypic variation for flesh colour. In family four, both parents appeared to be segregating for the QTL (table 4). The flesh colour averages for the different progeny genotypes (representing $Q Q, Q q$ and $q q$ 


\begin{tabular}{|c|c|}
\hline \multirow[b]{2}{*}{ SCARB1 } & TM-1 (aa 13-35) \\
\hline & MNKSKLA GLFVAGTLTAVFGLVIVFVGPI I IDDQIVKNLVIDPKNE SY - 50 \\
\hline SCARB1-2 & MNKSKLAVGLLVVGTLTVVFGTV VFVGPIIIDNQIVKNLVIDPKNE SY - 50 \\
\hline & LNPTEVLAGEKPMVEQRGPYVYRKR QKQNI-100 \\
\hline B1-2 & TMWKD V PVPFMSVYFFN LNPTEVLAGEKPMVEQRGPYVYRKR QKQNI-100 \\
\hline & TEHPNDTVSYLEYRSYFFEPSMSVGNESDVVT I PNMLVLGAAVMMEN PI-150 \\
\hline B1-2 & TFHPNHTVSYLEYRSYFFEPSMSVGNESDVVT I PNMLVLGAAVMMEN PF-150 \\
\hline$P \perp$ & AVRL SATFKGFKEGPFL KSVGELMWGYDSKLVDFLNKWFPGMLPSTG-200 \\
\hline $31-2$ & PVRLM STTFKTFKEGPFL KSVGKLMWGYDSKLVDFLNKWLPGMLPSTG-200 \\
\hline $\mathrm{SCA}$ & KFGLFTEFNNSNTGLFT HTGKDDIRLIHKVNSWNG TKLIYWR TPQCNM-2 50 \\
\hline $1-2$ & KFGLFAEFNNSNTGLFT HTGEDDIRLIHKVDSWNG TKLTNW TPQCNM-2 50 \\
\hline & INGTAGQMWPPFMTKESTLPFYSPDACRSLE VYQREGTMKGI PLYR VA-300 \\
\hline SCARB1 - 2 & INGTAGQMWPP FMTKESTLPFYSPDACRSLE VYQREGIMEGIPLYR VA-300 \\
\hline & PKTMFANGSDYAPNEGFCPCRQSGLLNVSSCR N QVFISQPHFYNADPV- 350 \\
\hline RB1-2 & PKT FANGSDYPPNEGFCPCRQSGLLNVSSCR N PVFISHPHFYNADPV- 350 \\
\hline SCA & LLDYVQGLQPTEDEHGLFIDIHPETGVPLNVS IRLQLNLYMKKVSGITET-40 \\
\hline SCARB1 - 2 & LLDYVQGLQPTEDQHGLFIDIHPETGVPLNVS IRLQLNLYMKKVSGITET-400 \\
\hline & $\begin{array}{lll}2 & \mathbf{T M}-2\end{array}$ \\
\hline $\mathrm{SCA}$ & GKISEV MPM WFEENGY DGAI KTFHTNLVLLPKVMVYMQYCF GLGL- 450 \\
\hline SCARE & GKISEV MPM WEEENGY DGEI TTFHTNLVLLPMVMVYMQYCF VLGL-4 50 \\
\hline & $($ aa $440-462) \vdots$ \\
\hline & AT VGVVLL YRGKIIKCERTVIPDASVSTSSSEQTPLIQDPVD \\
\hline $\mathrm{SCAR}$ & AT LGAVLL YRKKASVKDTVNSADALKQDGQMYRE \\
\hline
\end{tabular}

Figure 1 The amino-acid (aa) sequence alignment of Atlantic salmon SCARB1 and the novel paralog, SCARB1-2. The amino-acid (aa) sequence alignment of Atlantic salmon SCARB1 [NP_001117084] and SCARB1-2 [ADQ20116] shows that the sequences are 89\% identical. 26 out of the 51 diverging aa are non-conservative (black letters in bold on white background), while the rest are conservative changes (white, underlined letters). Transmembrane domains (TM) are indicated by the vertical arrows.

Table 2 Genotypes of the founding parents

\begin{tabular}{|c|c|c|}
\hline Parents & Sequence & $\begin{array}{l}\text { Genotype } \\
\text { (bp) }\end{array}$ \\
\hline P11 (Bleke) & $\begin{array}{l}\text { GGCGAGGGTGAGTGGGCGAGGG } \\
\text { TGAGTG }\end{array}$ & 763,763 \\
\hline $\begin{array}{l}\text { P31 } \\
\text { (AquaGen) }\end{array}$ & $\underline{\text { CGAGCGAGAGGGTGGGCGAGAGGG }}$ & null, null \\
\hline P14 (Bleke) & not sequenced & 619,634 \\
\hline $\begin{array}{l}\text { P34 } \\
\text { (AquaGen) }\end{array}$ & CGAGCGAGAGGGTGAGTGGG & null, null \\
\hline P15 (Bleke) & $\begin{array}{l}\text { GGCGAGGG TGAGTGGGCGAGGG } \\
\text { TGAGTG }\end{array}$ & 623,623 \\
\hline $\begin{array}{l}\text { P35 } \\
\text { (AquaGen) }\end{array}$ & CGAGCGAGAGGG TGAGTGGG & null, null \\
\hline
\end{tabular}

Genotypes of the founding parents (SALBANK) in the Bleke and Atlantic salmon commercial lines (AquaGen). Null genotypes represent non-amplifying alleles in the mapping population. The SCARB1-2 alleles, ranged in size from 623 to763 bp, and comprise the enhancer of zeste consensus motif (EZH2) [T/ $\mathrm{C}] \mathrm{GAG}[\mathrm{T} / \mathrm{C}][\mathrm{G} / \mathrm{T}]$ (underlined). The sequence of the repetitive EZH2-elements diverges for Bleke and the commercial Atlantic salmon.
QTL allele combinations), indicated that the QTL alleles conferring redder flesh were inherited from both the Bleke and commercial founding parents in the two F1 parents.

\section{SCARB1 and SCARB1-2 mRNA in Atlantic salmon tissues}

The expression pattern of SCARB1 and SCARB1-2 transcripts in liver, mid gut and muscle of commercial Atlantic salmon slaughtered prior to sexual maturity (NIVA fish) was investigated by real-time PCR. We chose the NIVA-fish as a reference population due to lack of tissues for RNA-extraction from the QTL-mapping population. Pair wise comparisons of the gene expression for each of the two paralogs revealed a fivefold increased expression of SCARB1 mRNA in mid gut, compared to that in muscle and liver $(\mathrm{p}<0.01)$ (Figure 4). In contrast, the SCARB1-2 mRNA was about equally expressed in liver, muscle and mid gut (Figure 4). The 


\section{Chr1-F1}

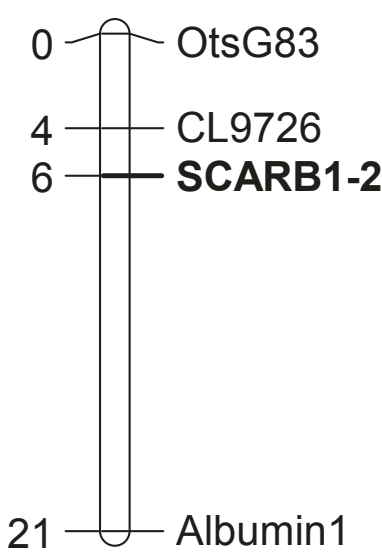

\section{Chr1-F2 Chr1-M}

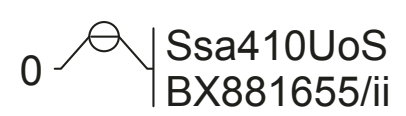

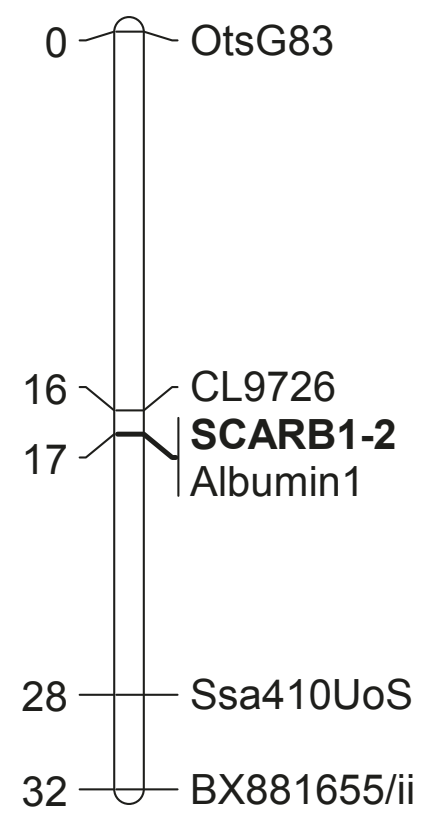

Figure 2 Position of SCARB1-2 on the male and female chromosome 1 linkage maps. The relative position of SCARB1-2 on the male(M) and female(F) chromosome 1 linkage maps used in this study. Chr1-F1 and Chr1-F2 represent two unlinked segments in the female map.

$\mathrm{Ct}$ values in the real-time PCR analysis were about a ten-fold lower for SCARB1-2 mRNA, compared to $S C A R B 1$, and demonstrate an overall increased mRNA expression of SCARB1, compared to that of SCARB1-2.

\section{Discussion}

The founding parents of the SALBANK resource population were screened for genetic variation in SCARB1 and revealed the presence of genetic variation in an adjacent novel paralog, which we named SCARB1-2. A total of seven different SCARB1-2 alleles were identified in the founder individuals, and the alleles diverged for the Bleke-and the commercial Atlantic salmon line as shown in table 2. Baranski et al. [30] found suggestive evidence (chromosome-wide significance) for a QTL with relatively large allele substitution effects in individual parents on this linkage group, and the addition of the SCARB1-2 marker data provided evidence for QTL segregation in a third parent, through increasing the information content in this family. Given that the QTL peak in both the sire and dam analyses is less than 10 $\mathrm{cM}$ from the position of SCARB1-2 (only $2 \mathrm{cM}$ in the dam analysis) (Figure 3), SCARB1-2 represents a putative candidate gene for this QTL-region, however the large confidence intervals around the QTL peak imply that numerous other genes in this region could underly the QTL. Indeed, this large confidence interval is also reflected in the different positions of the QTL peaks in the two sexes, which can be explained by the substantial map difference between the sexes, and the differing levels of marker and QTL informativeness in the F1 parents. The tracing of the 'positive' allele to both the commercial and landlocked lines provides evidence for the heterozygosity of this QTL within the lines. This is not particularly surprising given the lines are outbred, and information on the carotenoid uptake of pure Bleke fish in an environment with ample pigment 'available' in the feed would be valuable information in further characterising the effect of environment versus genetics for this trait. Baranski et al. [30] also reported numerous other suggestive and significant QTL affecting this trait, suggesting a polygenic effect where genetic variation at other loci contributes substantially to the phenotypic variance observed.

Comparing the sequence identity of $S C A R B 1$ from aa position 1 to 462 to that of $S C A R B 1-2$, revealed an overall $89 \%$ sequence identity. Half of the diverging aa are of similar, or conservative character, while the remaining half is of dissimilar, or non-conservative character. The most diverging $\mathrm{C}$-terminal region extends from aa 463 to the stop codon at aa 486. This C-terminal region comprises the cytoplasmic tail of the protein which has been shown to interact with proteins that can modulate localisation, stability and function of SCARB1 [31]. The 


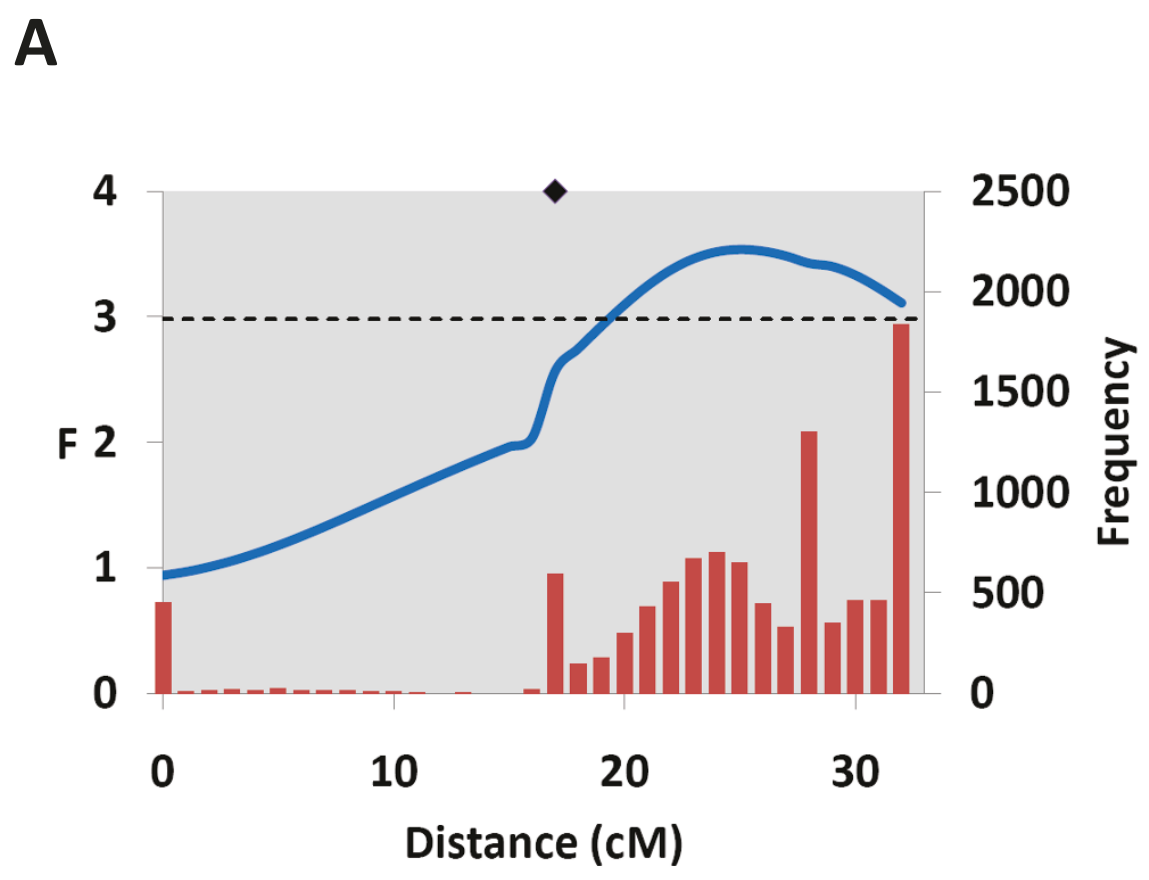

B

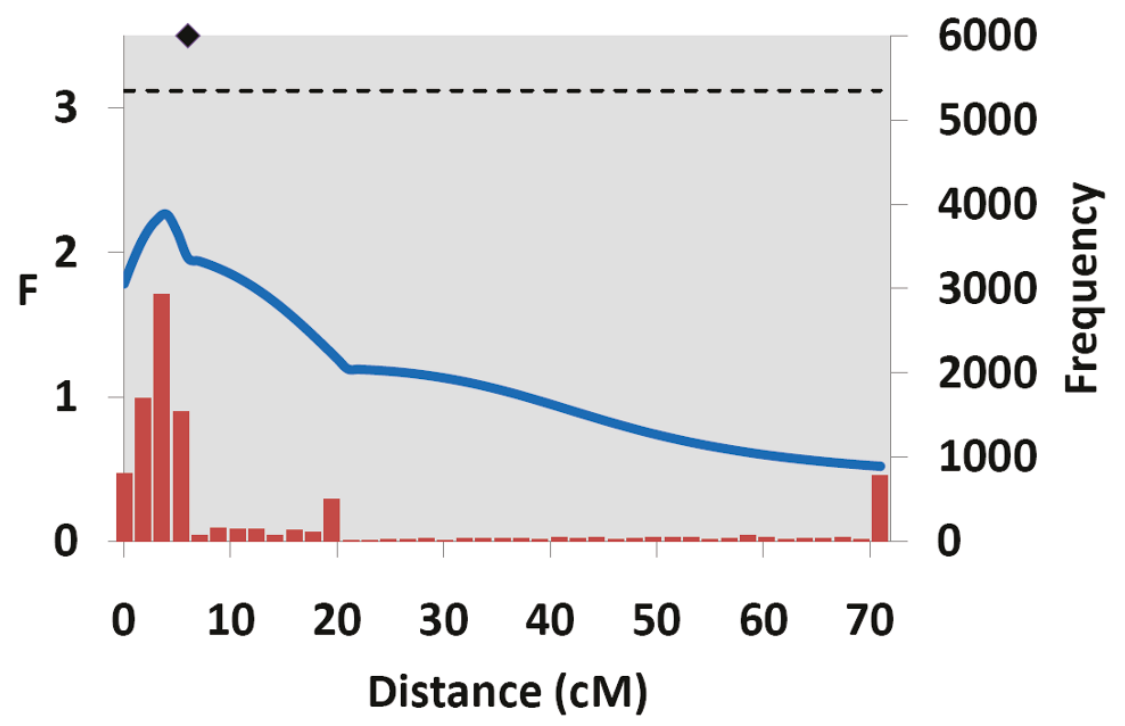

Figure 3 QTL analysis of Atlantic salmon chromosome 1. F-statistic profiles (blue lines) and QTL position bootstrap frequencies (red bars) for the male (A) and female (B) chromosome 1 linkage maps. Chromosome-wide significance thresholds are indicated by the horizontal broken lines. The position of SCARB1-2 is indicated by a black diamond on the upper $\mathrm{x}$ axis.

relatively high degree of non-synonymous aa-substitutions, particularly in the C-terminal cytoplasmic tail, suggests that the two paralogs diverge in function. It has previously been hypothesised that flesh pigmentation is linked to the presence of a duplicated genome, as pigmentation appears to be found only in the genera Salmo, Oncorhyncus, Salvelinus and Hucho, those exhibiting partly tetrasomic inheritance [5]. Thus, it is possible that the genetic basis causing variation in flesh colour may be partly due to a duplicated gene like SCARB1-2. 
Table 3 QTL segregating parents and estimates of QTL effects

\begin{tabular}{llll}
\hline Parent & Estimate & SE & ABS(t) \\
\hline M1 & $\mathbf{0 . 8 9}$ & $\mathbf{0 . 3 7}$ & $\mathbf{2 . 4}$ \\
\hline M2 & 0.53 & 0.37 & 1.4 \\
\hline M3 & 0.18 & 0.44 & 0.4 \\
\hline M4 & $\mathbf{1 . 0 2}$ & $\mathbf{0 . 4 1}$ & $\mathbf{2 . 5}$ \\
\hline F1 & 0.01 & 0.37 & 0.0 \\
\hline F2 & 0.06 & 0.37 & 0.2 \\
\hline F3 & 0.04 & 0.42 & 0.1 \\
\hline F4 & $\mathbf{1 . 1 0}$ & $\mathbf{0 . 3 7}$ & $\mathbf{3 . 0}$ \\
\hline
\end{tabular}

QTL effect estimates and absolute t-values for the eight parents analysed (segregating parents in bold).

Immunochemical methods have shown that SCARB1 is most highly expressed in adult mammalian tissues that are the principal sites of selective lipid uptake in vitro, i.e., the intestine, liver and steroidgenic tissues [32]. Studies in SCARB1 deficient mice and cell lines provide evidence for an involvement of SCARB1 in intestinal carotenoid absorption [25,26,33]. We found the most prominent expression of SCARB1 mRNA in the mid gut consistent with previous report on SCARB1 mRNA expression in Atlantic salmon [21]. The mid gut has been shown to be the main site of fat digestion and absorption in Atlantic salmon [33,34]. In skeletal muscle and liver the SCARB1-1 mRNA was reduced with a fivefold, compared to its expression in the intestine in Atlantic salmon (Figure 4). Interestingly, the SCARB1-2 mRNA level in muscle equals its expression in liver and mid gut, but is expressed at a considerably lower level than SCARB1 mRNA.

The different SCARB1-2 alleles, ranging in size from 619 to $763 \mathrm{bp}$, comprise repetitive sequences consisting of distinct enhancer of zeste motifs (EZH2) with the consensus sequence (T/C/g)GAGTG(A/G/c), recognized by the sequence-specific DNA-binding protein zeste. Zeste expression is developmentally regulated in skeletal muscle [35], and it has been shown that EZH2 is involved in controlling muscle gene expression and differentiation through removal of an actively suppressing HKMT protein complex containing Polycomb EZH2, and the subsequent engagement of positive

Table 4 Average SalmoFan scores for progeny genotype groups in the family with two QTL heterozygous parents

\begin{tabular}{lll}
\hline Genotype & $\mathbf{6 2 3}(\mathbf{Q})$ & null (q) \\
\hline $\mathbf{6 3 4}(\mathbf{q})$ & $24.3(\mathrm{Qq})$ & $23.5(\mathrm{qq})$ \\
\hline null (Q) & $26.5(\mathrm{QQ})$ & $24.8(\mathrm{Qq})$ \\
\hline
\end{tabular}

Average SalmoFan values (uncorrected for body weight) for the different progeny genotype groups at SCARB1-2 in the family where both parents were QTL heterozygous. The inferred QTL allele is shown next to the SCARB1-2 marker allele for parents F4 (side) and M4 (top). transcriptional regulators characteristic for the activation of muscle gene expression [36]. It can be speculated that distinct SCARB1-2 alleles comprising these regulatory motifs may differently affect SCARB1-2 mRNA expression, and in turn, the cellular uptake of astaxanthin. However, the mapping results from this study are insufficient to confirm such an association, and further studies are needed to elucidate the effect of these regulatory motifs on the gene expression.

\section{Conclusions}

Flesh pigmentation is an important quality trait in commercial Atlantic salmon that could be improved through elucidation of underlying genetic polymorphisms associated with the trait. SCARB1 has a key role in the cellular uptake of carotenoids in homologous systems. We here present a novel paralog of SCARB1, SCARB1-2 and identify alleles comprising repetitive enhancer of zeste motifs. These alleles were used to map SCARB1-2 to Atlantic salmon chromosome 1, a region containing a suggestive QTL for flesh colour based on a previous study. Inclusion of the SCARB1-2 marker strengthened the evidence for the presence of this QTL and is a potential candidate gene, however studies using a higher density marker coverage and larger experimental population will be needed to confirm association of the reported polymorphisms to flesh pigmentation over the large number of other genes in this chromosomal region. Gene expression analysis showed that SCARB1-2 mRNA was equally expressed in Atlantic salmon muscle, liver and mid gut, while SCARB1 mRNA was more prominent in the mid gut. Ultimately, further understanding of the molecular mechanisms involved in flesh pigmentation of salmonids will have direct benefits for genetic improvement of this trait and add valuable knowledge to our understanding of its evolutionary history.

\section{Methods}

\section{Mapping population}

The mapping population consisted of four F2 families that originated from a cross between two divergent populations of Atlantic salmon in Norway, the 'ancient', landlocked Byglands Bleke population and a commercial selected line, a resource population known as 'SALBANK'. These two populations are highly divergent for a number of traits, including flesh colour and growth, and the F2 population was created as a mapping resource with an increased likelihood of segregation at QTL affecting these traits. The details of the pedigree, phenotypic recording and sampling procedures can be found in Baranski et al. [30]. Fifty progeny from each extreme of the flesh colour distribution, measured visually using the Roche SalmoFan, were selected from 


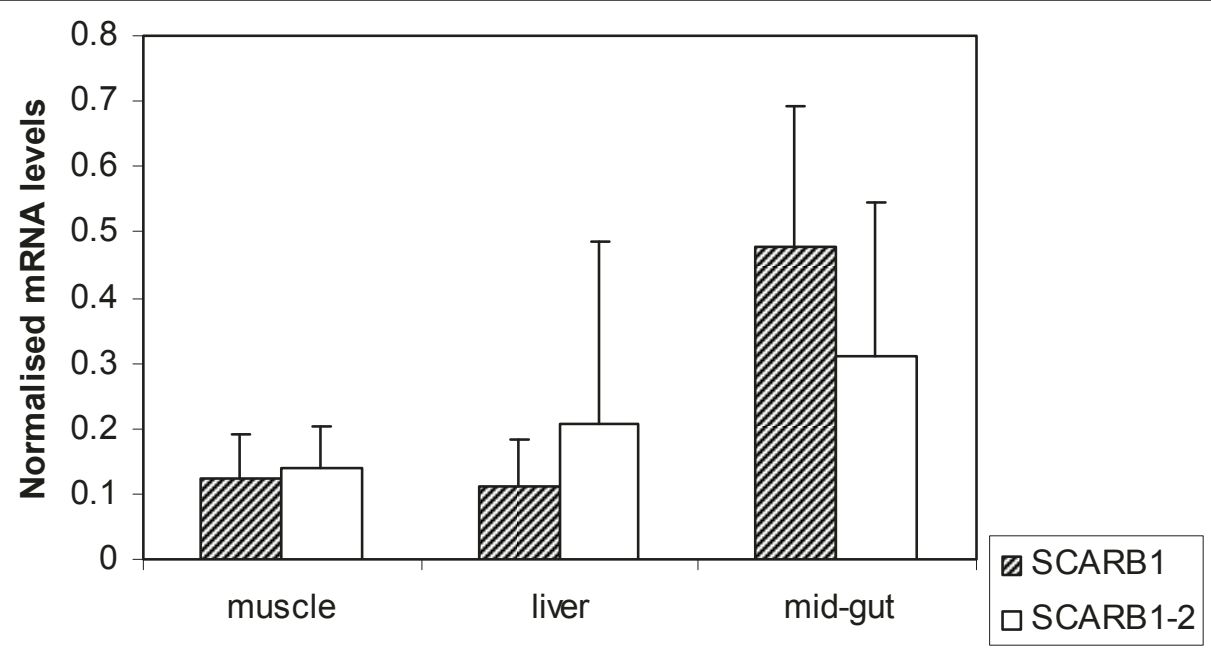

Figure 4 Normalised expression of SCARB1 and SCARB1-2 transcripts in Atlantic salmon tissues. Real-time PCR analyses showing the normalised SCARB1 and SCARB1-2 mRNA levels in Atlantic salmon muscle, liver and mid gut $(n=7-10)$, calculated by the $2^{-\triangle A C t}$ method and adjusted for PCR efficiencies. When comparing the gene expression in mid gut, muscle and liver for each paralog using one-way ANOVA, SCARB1 was found to be significantly increased in midgut compared to muscle and liver $(P<0.01)$. Average values of three independent $q P C R$ runs were used for the calculation.

three F2 families (8B, 9B and 10B), and all 76 progeny from a fourth family (10A) were selected for genotyping. Due to differences in progeny numbers between the families, this represented selective genotyping fractions (both extremes) of 44\%, 35\%, 35\% and 100\% respectively for the four families.

\section{Atlantic salmon tissues (NIVA fish)}

The NIVA-fish served as a reference population (normal breeding population) since we did not have tissues for RNA from the actual QTL-mapping population. Tissues for total RNA-isolation were collected from Atlantic salmon with an average weight of 1000 grams (before sexual maturation), kept in tanks at $12^{\circ} \mathrm{C}$ at NIVAs Research station, Drøbak, Norway. Muscle, liver and mid gut were collected from ten fish, and immediately stored on liquid nitrogen and subsequently transferred to $-80^{\circ} \mathrm{C}$ until RNA-extraction.

\section{DNA extraction}

Genomic DNA was isolated from about $20 \mathrm{mg}$ muscle of Atlantic salmon, using either MagAttract DNA M48 Tissue kit on the Bio-Robot M48 (Qiagen, Hilden, Germany) or DNeasy 96 protocol (Qiagen, Hilden, Germany). Prior to isolation, muscle samples were lysed in Proteinase $\mathrm{K}$ at $56^{\circ} \mathrm{C}$ over night according to the manufacturer's protocol. Insoluble materials after lysis were removed by centrifugation $(300 \times g, 1$ minute). DNA was extracted according to manufacturer's instruction with the inclusion of RNaseA $(0.1 \mathrm{mg} / \mathrm{sample}$ RNase A R5503 (Sigma-Aldrich, St. Louis, MO, USA)), for 30 minutes at room temperature.

\section{Oligonucleotide design}

Oligonucleotides used for PCR-amplification of intron sequences were designed based on Atlantic salmon SCARB1 [Genbank:DQ914655.1] using Vector NTI Advance (Invitrogen, Carlsbad, CA, USA). Putative exon-intron junctions for intron three, four, five and ten were identified by comparative sequence alignment to the human SCARB1 reference sequence [Genbank: NM_005505]. For real-time PCR analysis oligonucleotides were designed to span one intronic sequence in order to keep control of any potential genomic contamination in the RNA samples.

\section{PCR}

PCR-amplification was carried out using $0.4 \mu \mathrm{M}$ oligonucleotides, $0.05 \mathrm{U} / \mu \mathrm{l}$ Taq Gold, $200 \mu \mathrm{M}$ dNTPs and 1 $\times$ reaction buffer containing $15 \mathrm{mM} \mathrm{MgCl}_{2}$ (Applied Biosystems, Foster City, CA, USA). After 10 minutes of initial denaturation at $95^{\circ} \mathrm{C}, 40$ cycles of amplification at $95^{\circ} \mathrm{C}$ for 30 seconds, $54-60^{\circ} \mathrm{C}$ for 30 seconds, $72^{\circ} \mathrm{C}$ for 30-60 seconds was followed by a final extension of 7 minutes at $72^{\circ} \mathrm{C}$. The PCR-product was fractionated on a $2 \%$ agarose gel containing ethidium-bromide and visualised by UV-transiluminator 2000 (BIORAD).

\section{DNA sequence analysis}

Prior to sequencing, the PCR-products were purified using Montage PCR Genomics cleanup kits (Millipore, Billerica, MA, USA), according to the manufacturer's protocol. DNA-sequencing was performed using the BigDye Terminator version 3.1 cycle sequencing kit according to the manufacturer's protocol with the 
following thermocycling conditions: $96^{\circ} \mathrm{C} 1$ minute, 25 cycles at $96^{\circ} \mathrm{C}$ for 45 seconds, $50^{\circ} \mathrm{C}$ for 45 seconds and $60^{\circ} \mathrm{C}$ for 4 minutes. The products were purified with Montage-SEQ96 cleanup kits (Millipore, Billerica, MA, USA) and sequencing was performed on a 3730 DNA Analyser (Applied Biosystems, Foster City, CA, USA).

\section{RNA-isolation and cDNA-synthesis}

Total RNA was isolated using a combined protocol with Trizol and RNeasy mini kit, and DNAse-treated using the RNase-free DNase set as described by the manufacturer (Invitrogen, Carlsbad, CA, USA). RNA quantity was measured using the NanoDrop ND-1000 Spectrophotometer (NanoDrop Technologies, Wilmington, DE, USA) and quality was examined by the $28 \mathrm{~S}: 18 \mathrm{~S}$ rRNA ratio using the RNA 6000 Nano LabChip ${ }^{\circledR}$ Kit on 2100 Bioanalyser (Agilent Technologies, Santa Clara, CA, USA). First strand cDNA synthesis was performed using SuperScript ${ }^{\mathrm{TM}}$-II Rnase H-Reverse Transcriptase (Invitrogen, Carlsbad, CA, USA) and oligo-dT oligonucleotide T270 (5'-GACTCGAGTCGACATCGATTTTTTT TTT-TTTTTTT-3'). $0.25 \mu \mathrm{g}$ of total RNA was used as template for cDNA-synthesis, all RNA was standardised to the same concentration prior to cDNA-synthesis.

\section{Quantitative Real-Time PCR}

Real-Time PCR was conducted using LC480 (Roche) and gene-specific oligonucleotides using oligonucleotide combination 2 and 5, for SCARB1 and SCARB1-2, respectively (table 1). Oligonucleotide and cDNA-concentration were optimised to obtain the lowest possible Ct-value. 0.4-1.25 $\mu \mathrm{M}$ of each oligonucleotide, $2 \mu \mathrm{l}$ of $2 \times$ SYBR Green PCR Mastermix (Applied Biosystems, Foster City, CA, USA) and the cDNA-template were mixed in a total volume of $12 \mu \mathrm{l}$. A two-step PCR was run for 45 cycles $\left(10 \mathrm{~s}\right.$. at $95^{\circ} \mathrm{C}$, $30 \mathrm{~s}$. at $65-67^{\circ} \mathrm{C}$ ) with an initial denaturation of $10 \mathrm{~min}$. at $95^{\circ} \mathrm{C}$. Specificity of the PCR-products was verified by agarose gel-electrophoresis and amplicon sequencing. Standard curves for each oligonucleotide pair were generated by serial dilution $(1,1: 2,1: 10)$ of cDNA consisting of a pool of the representative samples, and PCR efficiencies $(E)$ were calculated according to the formula $\mathrm{E}=10^{(-1 / \text { slope(a)) }}$ [37]. E-values was 0.7 for $S C A R B 1$ and for $S C A R B 1-2$, and comprise $C t$-values ranging from 21 to 27 , and from 30 to 34 , respectively. Relative mRNA expression was calculated by the $2^{-\Delta \Delta C t}$ method [38] adjusted for PCR efficiencies. 18S was used as a reference gene. Two independent cDNAsyntheses of each sample were performed. Two independent PCR reactions were run for each cDNA synthesis with duplicate samples within each PCR.

\section{Statistics}

Statistical analyses of the qPCR results were carried out using a GenEx software package (MultiD Analyses AB,
Sweden). The samples were already normalized to reference gene (18S) and PCR efficiency when imported into GenEx. The samples were normalized for technical replicates (and missing data), and calculated using the average of three independent qPCR runs. One-way ANOVA, with post test all pairwise comparisons (Tukey-Kramer's) was used to compare the gene expression in mid gut, muscle and liver, for each of the two paralogs.

\section{Linkage mapping and QTL analysis}

Genotyping of the SCARB1-2 locus was carried out on the 'SALBANK' founder parents and F2 progeny with thermocycling conditions $95^{\circ} \mathrm{C} 10 \mathrm{~min} ., 40$ cycles of $95^{\circ} \mathrm{C} 30$ sec., $60^{\circ} \mathrm{C} 30$ sec., $72^{\circ} \mathrm{C} 30$ sec., and $72^{\circ} \mathrm{C} 10$ min., using oligonucleotide combination 5 shown in table 1 . The lengths of the fluorescent PCR products were determined relative to the LIZ1200 size standard (Applied Biosystems, Foster City, CA, USA) on a 3730 DNA Analyzer (Applied Biosystems), using GeneMapper 4.0 (Applied Biosystems) software for allele calls. Genotypes of the F1 parents were inferred from the grandparent and offspring genotypes. The SCARB1-2 genotype data was added to the microsatellite data previously genotyped for these individuals [30], and linkage analysis was performed in Joinmap 3.0 using a minimum LOD score of 3.0 in order to map the SCARB1-2 locus to the Atlantic salmon linkage map. In order to evaluate QTL linkage with the hypothesis that a QTL peak is located at this marker position, half-sib regression interval mapping for the linkage group containing the $S C A R B 1-2$ locus was carried out in GridQTL at 1 cM intervals [39], with sex fitted as a fixed effect and body weight as a covariate due to a strong positive phenotypic correlation between body weight and colour. Separate male and female analyses were performed due to the map differences observed in the sexes. $50 \mathrm{cM}$ distance was inserted between the unlinked pair of markers in the female map and marker Albumin 1 in the first group. Significance thresholds were estimated after 10,000 chromosome-wide permutation tests. Parents segregating for the QTL were identified based on their individual $t$-values in the GridQTL analysis. Confidence intervals (CI) were estimated for the QTL using the bootstrap method and 10,000 iterations [40]. The proportion of phenotypic variance explained by the QTL using the half-sib model was calculated as $\left(2 *\left(1-\mathrm{MS}_{\text {full }} / \mathrm{MS}_{\text {reduced }}\right)^{\text {sire }}\right)+$ $\left.\left(1-\mathrm{MS}_{\text {full }} / \mathrm{MS}_{\text {reduced }}\right)^{\mathrm{dam}}\right)[41]$.

\section{Abbreviations}

aa: amino-acids; bp: base pairs; cM: centi Morgan; EZH2: enhancer of zeste motifs; kb: kilobases; n.p.: nucleotide position; QTL: quantitative trait loci; RTPCR: reverse-transcriptase polymerase chain reaction; SCARB1: scavenger 
receptor class B, member 1, paralog 1; SCARB1-2: scavenger receptor class B, member 1, paralog 2; SNP: single nucleotide polymorphism

\section{Acknowledgements}

This study was funded by the Norwegian Research Council (177036/S10), who also provided access to the SALBANK samples. Genomar AS and Nofima Marin (Averøy) produced the families and performed the trait recording. We also thank Bjørn Høyheim and Anna Sonesson for storage and registration of samples and data.

\section{Author details}

${ }^{1}$ Centre for Integrative Genetics, Dept. of Animal and Aquacultural Sciences, Norwegian University of Life Sciences, 1432 Aas, Norway. ${ }^{2}$ Nofima Marin, 1432 Aas, Norway.

\section{Authors' contributions}

HS performed the design of the study, carried out the molecular genetic studies and drafted the manuscript. $\mathrm{HH}$ performed parts of the molecular genetic studies and helped to draft the manuscript. MB performed the linkage mapping, QTL analysis and helped to draft the manuscript. DIV and SWO conceived the study and participated in its design and coordination and helped to draft the manuscript. All authors have read and approved the final manuscript.

Received: 18 November 2010 Accepted: 30 May 2011 Published: 30 May 2011

\section{References}

1. Torrissen OJ, Christiansen R: Requirements for carotenoids in fish diets. Journal of Applied Ichthyology-Zeitschrift Fur Angewandte Ichthyologie 1995, 11(3-4):225-230

2. Spinelli J, Mahnken C: Carotenoid deposition in pen-reared salmonids fed diets containing oil extracts of red crab (pleuroncodes-planipes). Aquaculture 1978, 13(3):213-223

3. Choubert G, Luquet P: Feeding test of capelin oil (mallotus-villosus m) on rainbow-trout-amount and qualities of carotenoid contents in muscle and skin. Annales D Hydrobiologie 1975, 6(2):123-130.

4. Garcia de Leaniz C, Fleming IA, Einum S, Verspoor E, Jordan WC, Consuegra S, Aubin-Horth N, Lajus D, Letcher BH, Youngson AF, et al: A critical review of adaptive genetic variation in Atlantic salmon: implications for conservation. Biological Reviews 2007, 82(2):173-211.

5. Rajasingh $\mathrm{H}$, Oyehaug L, Vage DI, Omholt SW: Carotenoid dynamics in Atlantic salmon. BmC Biology 2006, 4.

6. Aas GH, Bjerkeng B, Storebakken T, Ruyter B: Blood appearance, metabolic transformation and plasma transport proteins of C-14-astaxanthin in Atlantic salmon (Salmo salar L.). Fish Physiology and Biochemistry 1999, 21(4):325-334

7. Parker RS: Carotenoids.4. Absorption, metabolism, and transport of carotenoids. Faseb Journal 1996, 10(5):542-551.

8. Clevidence BA, Bieri JG: Association of carotenoids with human plasmalipoproteins. Methods in Enzymology 1993, 214:33-46.

9. Borel P, Grolier P, Armand M, Partier A, Lafont H, Lairon D, AzaisBraesco V: Carotenoids in biological emulsions: Solubility, surface-to-core distribution, and release from lipid droplets. Journal of Lipid Research 1996, 37(2):250-261.

10. Breithaupt $D E$, Bamedi $A$ : Carotenoid esters in vegetables and fruits: $A$ screening with emphasis on beta-cryptoxanthin esters (vol 49, pg 2064, 2001). Journal of Agricultural and Food Chemistry 2001, 49(5):2686-2686

11. Matsuno T: Xanthophylls as precursors of retinoids. Pure and Applied Chemistry 1991, 63(1):81-88

12. Schiedt K, Leuenberger FJ, Vecchi M, Glinz E: Absorption, retention and metabolic transformations of carotenoids in rainbow-trout, salmon and chicken. Pure and Applied Chemistry 1985, 57(5):685-692.

13. Miki W: Biological functions and activities of animal carotenoids. Pure and Applied Chemistry 1991, 63(1):141-146.

14. Shimidzu N, Goto M, Miki W: Carotenoids as singlet oxygen quenchers in marine organisms. Fisheries Science 1996, 62(1):134-137.

15. Ando S, Takeyama T, Hatano M: Deterioration of chum salmon muscle during spawning migration.9. Isolation and characterization of a carotenoid-carrying lipoprotein in the serum of chum salmon (oncorhynchus-keta) during spawning migration. Agricultural and Biological Chemistry 1986, 50(4):907-914.

16. Torrissen OJ, Naevdal G: Pigmentation of salmonids-variation in flesh carotenoids of atlantic salmon. Aquaculture 1988, 68(4):305-310.

17. Goodwin TW: Developments in carotenoid biochemistry over 40 years. Biochemical Society Transactions 1983, 11(5):473-483.

18. Slifka KA, Bowen PE, Stacewicz-Sapuntzakis M, Crissey SD: A survey of serum and dietary carotenoids in captive wild animals. Journal of Nutrition 1999, 129(2):380-390.

19. McCallum IM, Cheng KM, March BE: Carotenoid pigmentation in 2 strains of chinook salmon (oncorhynchus-tshawytscha) and their crosses. Aquaculture 1987, 67(3-4):291-300.

20. Hauser $H$, Dyer JH, Nandy A, Vega MA, Werder M, Bieliauskaite E, Weber FE, Compassi S, Gemperli A, Boffelli D, et al: Identification of a receptor mediating absorption of dietary cholesterol in the intestine. Biochemistry 1998, 37(51):17843-17850.

21. Kleveland EJ, Syvertsen BL, Ruyter B, Vegusdal A, Jorgensen SM, Gjoen T: Characterization of scavenger receptor class B, type I in Atlantic salmon (Salmo salar L.). Lipids 2006, 41(11):1017-1027.

22. Thuahnai ST, Lund-Katz S, Williams DL, Phillips MC: Scavenger receptor class B, type I-mediated uptake of various lipids into cells-Influence of the nature of the donor particle interaction with the receptor. Journal of Biological Chemistry 2001, 276(47):43801-43808.

23. Urban S, Zieseniss S, Werder M, Hauser H, Budzinski R, Engelmann B: Scavenger receptor $\mathrm{BI}$ transfers major lipoprotein-associated phospholipids into the cells. Journal of Biological Chemistry 2000, 275(43):33409-33415.

24. Kiefer C, Sumser E, Wernet MF, von Lintig J: A class B scavenger receptor mediates the cellular uptake of carotenoids in Drosophila. Proceedings of the National Academy of Sciences of the United States of America 2002, 99(16):10581-10586.

25. van Bennekum A, Werder M, Thuahnai ST, Han CH, Duong P, Williams DL, Wettstein P, Schulthess G, Phillips MC, Hauser H: Class B scavenger receptor-mediated intestinal absorption of dietary ss-carotene and cholesterol. Biochemistry 2005, 44(11):4517-4525

26. During A, Dawson HD, Harrison EH: Carotenoid transport is decreased and expression of the lipid transporters SR-BI, NPC1L1, and ABCA1 is downregulated in Caco-2 cells treated with ezetimibe. Journal of Nutrition 2005, 135(10):2305-2312.

27. Reboul E, Abou L, Mikail C, Ghiringhelli O, Andre M, Portugal H, JourdheuilRahmani D, Amiot MJ, Lairon D, Borel P: Lutein transport by Caco-2 TC-7 cells occurs partly by a facilitated process involving the scavenger receptor class B type I (SR-BI). Biochemical Journal 2005, 387:455-461.

28. Sakudoh T, lizuka T, Narukawa J, Sezutsu H, Kobayashi I, Kuwazaki S, Banno Y, Kitamura A, Sugiyama H, Takada N, et al: A CD36-related Transmembrane Protein Is Coordinated with an Intracellular Lipidbinding Protein in Selective Carotenoid Transport for Cocoon Coloration. Journal of Biological Chemistry 2010, 285(10):7739-7751.

29. Phillips RB, Keatley KA, Morasch MR, Ventura AB, Lubieniecki KP, Koop BF, Danzmann RG, Davidson WS: Assignment of Atlantic salmon (Salmo salar) linkage groups to specific chromosomes: Conservation of large syntenic blocks corresponding to whole chromosome arms in rainbow trout (Oncorhynchus mykiss). Bmc Genetics 2009, 10.

30. Baranski M, Moen T, Vage DI: Mapping of quantitative trait loci for flesh colour and growth traits in Atlantic salmon (Salmo salar). Genetics Selection Evolution 2010, 42.

31. Ikemoto M, Arai H, Feng DD, Tanaka K, Aoki J, Dohmae N, Takio K,

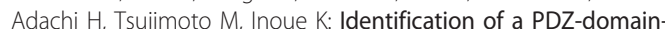
containing protein that interacts with the scavenger receptor class $B$ type I. Proceedings of the National Academy of Sciences of the United States of America 2000, 97(12):6538-6543.

32. Acton S, Rigotti A, Landschulz KT, Xu SZ, Hobbs HH, Krieger M: Identification of scavenger receptor SR-BI as a high density lipoprotein receptor. Science 1996, 271(5248):518-520.

33. Krogdahl A, Nordrum S, Sorensen M, Brudeseth L, Rosjo C: Effects of diet composition on apparent nutrient absorption along the intestinal tract and of subsequent fasting on mucosal disaccharidase activities and plasma nutrient concentration in Atlantic salmon Salmo salar L. Aquaculture Nutrition 1999, 5(2):121-133.

34. Denstadli V, Vegusdal A, Krogdahl A, Bakke-McKellep AM, Berge GM, Holm H, Hillestad M, Ruyter B: Lipid absorption in different segments of 
the gastrointestinal tract of Atlantic salmon (Salmo salar L.). Aquaculture 2004, 240(1-4):385-398.

35. Laible G, Wolf A, Dorn R, Reuter G, Nislow C, Lebersorger A, Popkin D, Pillus $L$, Jenuwein T: Mammalian homologues of the Polycomb-group gene Enhancer of zeste mediate gene silencing in Drosophila heterochromatin and at S-cerevisiae telomeres. Embo Journal 1997, 16(11):3219-3232.

36. Caretti G, Di Padova M, Micales B, Lyons GE, Sartorelli V: The Polycomb EA2 methyltransferase regulates muscle gene expression and skeletal muscle differentiation. Genes \& Development 2004, 18(21):2627-2638.

37. R R: Quantification on the Light cycler, in Rapid Cycle Real-time PCR: Methods and Applications. 2001

38. Livak KJ, Schmittgen TD: Analysis of relative gene expression data using real-time quantitative PCR and the 2(T)(-Delta Delta C) method. Methods 2001, 25(4):402-408.

39. Seaton G, Hernandez J, Grunchec JA, White I, Allen J, De Koning DJ, Wei W, Berry D, Haley C, Knott S: GridQTL: A Grid Portal for QTL Mapping of Compute Intensive Datasets. Proceedings of the 8th World Congress on Genetics Applied to Livestock Production, August 13-18, 2006 Belo Horizonte, Brazil 2006.

40. Visscher PM, Thompson R, Haley CS: Confidence intervals in QTL mapping by bootstrapping. Genetics 1996, 143(2):1013-1020.

41. Houston RD, Haley CS, Hamilton A, Guyt DR, Tinch AE, Taggart JB, McAndrew BJ, Bishop SC: Major quantitative trait loci affect resistance to infectious pancreatic necrosis in Atlantic salmon (Salmo salar). Genetics 2008, 178(2):1109-1115.

doi:10.1186/1471-2156-12-52

Cite this article as: Sundvold et al:: Characterisation of a novel paralog of scavenger receptor class B member I (SCARB1) in Atlantic salmon (Salmo salar). BMC Genetics 2011 12:52.

\section{Submit your next manuscript to BioMed Central and take full advantage of:}

- Convenient online submission

- Thorough peer review

- No space constraints or color figure charges

- Immediate publication on acceptance

- Inclusion in PubMed, CAS, Scopus and Google Scholar

- Research which is freely available for redistribution

Submit your manuscript at www.biomedcentral.com/submit
Biomed Central 